Journal of

Accident and

Emergency

Medicine 1995

12, 262-265

\title{
Attitudes of Dublin accident and emergency department doctors and nurses towards the services offered by local general practitioners
}

\author{
D. GIBNEY, ${ }^{1}$ A.W. MURPHY, ${ }^{1}$ M. SMITH, ${ }^{1}$ G. BURY ${ }^{1}$ P.K. PLUNKETT ${ }^{2}$ \\ 1 Department of General Practice, University College Dublin, Coombe Health Care Centre, Dublin 8 and \\ ${ }^{2}$ Department of Accident and Emergency Medicine, St. James' Hospital, Dublin 8, Ireland
}

\section{SUMMARY}

Good communication at the accident and emergency (A\&E)-general practice interface is important. Such communication will be affected by the attitudes of A\&E staff towards local general practitioners (GPs). The objectives of this study were to establish and compare, using a questionnaire, the attitudes of Dublin A\&E doctors and nurses towards the services offered by local GPs. A questionnaire was sent to all nurses and nonconsultant doctors working in four of the six Dublin A\&E departments. Completed questionnaires were received from $57(61 \%)$ nurses and $35(81 \%)$ doctors. Only two activities (being accessible to patients during normal surgery hours and providing family planning services) were rated by more than one-fifth of doctors and nurses as being performed 'well'. Six activities (being accessible to patients outside surgery hours, providing longterm care for the chronically ill and debilitated, providing appropriate care for 'difficult' patients, advising patients about the appropriate use of services and performing first aid) were rated by more than $40 \%$ of both doctors and nurses as being performed 'badly'. For all activities the nurses consistently rated the performance of the 'average GP' more critically than the doctors. These results must be interpreted cautiously. The implications of these findings and how best they can be addressed are discussed.

Key words: general practitioners, staff attitudes

Department of General Practice, University College Dublin, Coombe Health Care Centre, Dolphins Basin Street, Dublin 8, Ireland.
Feelings at the accident and emergency (A\&E)general practice interface can be fraught. Staff in
A\&E departments are managing ever-increasing number of patients who are neither accidents nor emergencies and whom they consider should have been treated within general practice. ${ }^{1,2}$ Dale and Green showed that A\&E nursing staff in six English hospitals perceived much of local general practice as being performed unsatisfactorily. ${ }^{3}$ General practitioners (GPs) in turn are frustrated by the increasing demands of out of hours work ${ }^{4}$ and the difficulties that they encounter in attempting to arrange hospital admission for acutely ill patients. ${ }^{5}$ They think that improved interface communications are a priority. ${ }^{6}$

Such communication will be affected by the attitudes of A\&E staff. Interface change will be dependent on the assessment and management of these attitudes. Although there is a high turnover of A\&E junior medical staff, their attitudes are important and do not appear to have been previously documented. The objectives of this study were to establish and compare the attitudes of Dublin A\&E doctors and nurses towards the services offered by local GPs.

\section{METHODS}

Four A\&E departments in Dublin City (the Mater, Meath, St. James' and James Connolly Memorial Hospitals) were approached and agreed to participate in the study. Together these four hospitals accounted for $64 \%$ of the total number of 306741 A\&E attendances in Dublin in 1991. ${ }^{7}$ A questionnaire was sent to all 93 nurses and 43 nonconsultant doctors working in the $A \& E$ departments of the four hospitals in July 1993. The questionnaires were anonymous and collected in sealed boxes for central analysis. Owing to the 
perceived sensitivity of the subject matter, a questionnaire coding system was not used to identify non-respondents. General reminders were placed on staff naticeboards.

Respondents recorded their sex, length of A\&E experience and length of employment in their current department. Seventeen statements outlining activities that may occur in general practice were then listed. These were based on the Leeuwenhorst definition of general practice and were previously used in the study by Dale and Green. ${ }^{3}$ For each activity respondents were asked to grade their perception of the performance of the 'average local GP' in their district. A three-point response scale (well, adequately and badly) was used.

Statistical analysis was performed on the EpiInfo 5.0b package. Respondents who did not answer a question were recorded as nonresponders. Non-responders were excluded from the statistical analysis of that question. To measure the extent of agreement and disagreement between the nurses and doctors for each question, $\chi_{2}$ tests were perfomed. This test will indicate if significant disagreement has occurred, but will not specify, within the responses to a given question, where that disagreement actually lies (e.g. in the well, adequately or badly column).

\section{RESULTS}

Completed questionnaires were received from 57 $(61 \%)$ nurses and $35(81 \%)$ doctors, an overall response rate of $68 \%$. All but one nurse was female, compared with $31 \%$ of doctors.

A total of $60 \%$ of doctors had less than 1 year of experience in an A\&E department; $55 \%$ of nurses had between 3 and 7 years of experience. Sixtysix per cent of doctors had been employed for less than a year in their current position. Fifty-three per cent of nurses had been working in their current position for between 3 and 7 years.

Table 1 gives the respondent ratings for each of the GP activities. Only two activities (being accessible to patients during normal surgery hours and providing family planning services) were rated by more than one-fifth of doctors and nurses as being performed well. Six activities (numbers 6, 7, $9,12,13$ and 14 ) were rated by over $40 \%$ of nurses and doctors as being performed badly. For all activities, the nurses rated the performance of the 'average GP' more critically than the doctors. Eight activities (numbers $1,2,6,8,9,11,12,14$ ) were rated by over $50 \%$ of nurses as being performed badly; two activities (numbers 6 and 14) were similarly rated by over $50 \%$ of doctors.

\section{DISCUSSION}

As the response rate was $68 \%$, the results may reflect the attitudes of those A\&E nurses and doctors who hold particularly strong views regarding local GPs. The different response rates of doctors and nurses may also be for the same reason. We have no details about non-respondents. We believe however, that interpreted cautiously, the results of this study are of relevance to the current debate regarding the A\&E-general practice interface.

Attitudes are important. The very negative attitudes reported in the Dublin study can, at best, hinder or, at worst, impede attempts to improve the quality of care provided at the A\&E-general practice interface. Of particular concern are the more negative attitudes among nursing staff. Stein was the first to describe the 'doctor-nurse game' in $1967 . .^{8}$ In a personal account, he outlined how nurses use subtle non-verbal and cryptic verbal cues to communicate recommendations to doctors, which in retrospect appear to have been initiated by the doctor. Hughes suggests that distinctive features of A\&E nursing lie in increased involvement in decision-making, which affects diagnosis and treatment, and in a qualitative shift in relations with medical staff. ${ }^{9} \mathrm{He}$ also showed that inexperienced doctors in particular depend on the advice of their nursing colleagues. The use of GP services by A\&E departments may therefore be particularly affected by the lack of confidence in them by nurses.

Such a lack of confidence may, of course, reflect real deficiencies in the services provided by Dublin GPs. This would be in direct contrast with the findings of a large survey of Dublin general practice attenders, who expressed a high level of satisfaction with the services they received. ${ }^{10}$ Such surveys do have significant methodological problems ${ }^{11}$ and may deal with a significantly different sample of patients or problems to those dealt with in A\&E departments.

Another possible explanation for the negative attitudes is the skewed view of primary care that A\&E staff receive. Patient perceptions or explanations for their A\&E attendances inevitably influence staff attitudes to general practice. This may partly explain the more negative attitudes of the nursing staff who had longer A\&E experience. Although GP-based surveys of the reasons for A\&E attendance suggest 
D. Gibney et al. Table 1. Rating of local general practitioner activities by Dublin accident and emergency department staff. Values are percentages of respondents

\begin{tabular}{|c|c|c|c|c|c|}
\hline General practitioner activity & $\begin{array}{c}\text { Respondent } \\
\text { (doctors, } n=35 \\
\text { nurses, } n=57 \text { ) }\end{array}$ & Well & Adequately & Badly & No response \\
\hline \multirow{2}{*}{$\begin{array}{l}\text { 1. Making appropriate referrals to the } \\
\text { A\&E Department }(P<0.005)\end{array}$} & 'Doctor’ & 14 & 60 & 23 & 3 \\
\hline & Nurse & 4 & 35 & 56 & 5 \\
\hline \multirow{2}{*}{$\begin{array}{l}\text { 2. Making appropriate referrals to } \\
\text { other hospital specialties }(P<0.005)\end{array}$} & 'Doctor’ & 9 & 63 & 20 & 9 \\
\hline & Nurse & 2 & 28 & 56 & 14 \\
\hline \multirow{2}{*}{$\begin{array}{l}\text { 3. Making good use of community } \\
\text { health services (e.g. PHN) (NS) }\end{array}$} & 'Doctor’ & 14 & 49 & 14 & 23 \\
\hline & Nurse & 11 & 46 & 33 & 10 \\
\hline \multirow{2}{*}{$\begin{array}{l}\text { 4. Being accessible to patients during } \\
\text { normal surgery hours (NS) }\end{array}$} & 'Doctor’ & 43 & 43 & 14 & 0 \\
\hline & Nurse & 21 & 61 & 16 & 2 \\
\hline \multirow[t]{2}{*}{ 5. Making home visits (NS) } & 'Doctor' & 20 & 43 & 32 & 6 \\
\hline & Nurse & 12 & 53 & 33 & 2 \\
\hline \multirow{2}{*}{$\begin{array}{l}\text { 6. Being accessible to patients } \\
\text { outside surgery hours (NS) }\end{array}$} & 'Doctor’ & 6 & 20 & 71 & 3 \\
\hline & Nurse & 3 & 18 & 79 & 0 \\
\hline \multirow{2}{*}{$\begin{array}{l}\text { 7. Providing long-term care for the } \\
\text { chronically ill and debilitated }(P<0.05)\end{array}$} & 'Doctor’ & 14 & 34 & 43 & 9 \\
\hline & Nurse & 2 & 47 & 44 & 7 \\
\hline \multirow{2}{*}{$\begin{array}{l}\text { 8. Registering 'difficult patients' } \\
\text { (eg addicts, homeless) }(P<0.0005)\end{array}$} & 'Doctor’ & 3 & 54 & 26 & 17 \\
\hline & Nurse & 0 & 23 & 63 & 14 \\
\hline \multirow{2}{*}{$\begin{array}{l}\text { 9. Providing appropriate care for } \\
\text { 'difficult' patients }(P<0.0005)\end{array}$} & 'Doctor’ & 6 & 45 & 40 & 8 \\
\hline & Nurse & 0 & 14 & 77 & 9 \\
\hline \multirow{2}{*}{$\begin{array}{l}\text { 10. Practising preventive medicine } \\
(P<0.005)\end{array}$} & 'Doctor’ & 17 & 51 & 20 & 11 \\
\hline & Nurse & 3 & 33 & 51 & 5 \\
\hline \multirow[t]{2}{*}{ 11. Providing self-care advice $(P<0.05)$} & 'Doctor’ & 14 & 54 & 20 & 12 \\
\hline & Nurse & 4 & 40 & 51 & 5 \\
\hline \multirow{2}{*}{$\begin{array}{l}\text { 12. Advising patients about the } \\
\text { appropriate use of services }(P<0.005)\end{array}$} & 'Doctor’ & 0 & 51 & 46 & 3 \\
\hline & Nurse & 5 & 19 & 76 & 0 \\
\hline \multirow{2}{*}{$\begin{array}{l}\text { 13. Providing first aid in the } \\
\text { surgery (NS) }\end{array}$} & 'Doctor' & 23 & 31 & 43 & 3 \\
\hline & Nurse & 9 & 42 & 49 & 0 \\
\hline \multirow[t]{2}{*}{ 14. Performing minor operations (NS) } & 'Doctor’ & 3 & 34 & 54 & 9 \\
\hline & Nurse & 0 & 23 & 75 & 2 \\
\hline \multirow{2}{*}{$\begin{array}{l}\text { 15. Recognizing and managing patients } \\
\text { with psychosocial problems (NS) }\end{array}$} & ‘Doctor’ & 14 & 43 & 29 & 14 \\
\hline & Nurse & 7 & 44 & 42 & 7 \\
\hline \multirow{2}{*}{$\begin{array}{l}\text { 16. Providing family planning } \\
\text { services (NS) }\end{array}$} & ‘Doctor’ & 31 & 46 & 9 & 14 \\
\hline & Nurse & 23 & 47 & 12 & 18 \\
\hline \multirow[t]{2}{*}{ 17. Prescribing appropriately $(P<0.05)$} & ‘Doctor’ & 34 & 51 & 11 & 3 \\
\hline & Nurse & 10 & 65 & 18 & 7 \\
\hline
\end{tabular}

NS, Not significant.

that dissatisfaction with GP services appears to play only a minor part in this decision-making, ${ }^{12,13}$ it is possible that different views are expressed to A\&E staff and that these views exert an inordinate influence on staff attitudes.

How applicable the findings are to other areas or countries is unclear. In general, Dublin nurses were more negative than their English colleagues. ${ }^{3}$ The six activities rated most critically were similar for the Dublin and English studies. There was less agreement about those areas considered to have
Morrison demonstrated that most GPs wish to have responsibility for their own patients for disorders that are neither accidents nor emergencies and are willing to attend joint meetings to improve interface communication. ${ }^{6}$ Reilly has noted that the more urgent task is not to inform GPs about A\&E services, but the converse, a point with which we would agree.

Accident and emergency departments should develop an accessible database of local community services and know how to contact them. The role of a liaison person, a representative of local general 
Attitudes towards GPs practice, paid for by the health authority on a sessional basis, to develop and improve communication at the interface should be evaluated. In St James's Hospital, local GPs have been employed on a sessional basis in the A\&E department in a similar role to that pioneered by King's College Hospital in London. ${ }^{15}$ By working together, it is hoped that old attitudes will be replaced by new respect and understanding. Although the numbers are small, a repeat of the survey in St James's showed an improvement in these attitudes. We also plan to repeat the survey in other hospitals intending to employ sessional GPs on a similar basis.

It is now more than $\mathbf{3 0}$ years since Blackwell asked for 'good hospital-general practitioner relationships'. ${ }^{16}$ This study suggests that such a simple aspiration has yet to be achieved.

\section{ACKNOWLEDGEMENTS}

We are grateful to Geoff Keyes, Derek Barton and Peter O'Connor for facilitating the survey in their departments and all the A\&E staff who completed the questionnaire.

\section{REFERENCES}

1. Driscoll P.A., Vincent C.A. \& Wilkinson M. (1989) The use of the accident and emergency department. Archives of Emergency Medicine 4, 77-82.

2. Foroughi D. \& Chadwick L. (1989) Accident and Emergency abusers. Practitioner 233, 657-658.

3. Dale J. \& Green J. (1991) How do nurses working in hospital accident and emergency departments perceive local general practitioners? - a study in six English hospitals. Archives of Emergency Medicine 8, 210-216.
4. Hallam L. (1994) Primary medical care outside normal working hours: review of published work. British Medical Journal 308, 249-253.

5. Jenkins C., Bartholomew J., Gelder F. \& Morrell D. (1994) Arranging hospital admission for acutely ill patients: problems encountered by general practitioners. British Journal of General Practice 44, 251-254.

6. Morrison W.G., Pennycook A.G., Makower R.M. \& Swann I.J. (1990) The general practitioner's use and expectations of an accident and emergency department. Journal of the Royal Society of Medicine 83, 237-240.

7. Department of Health (1992) Health Statistics 1991. Stationery Office, Dublin.

8. Stein L. (1967) The doctor-nurse game. Archives of General Psychology 16, 699-703.

9. Hughes D. (1988) When nurse knows best: some aspects of nurse/doctor interaction in a casualty department. Sociology of Health and IIIness. 10, 1-22.

10. Dun Laoghaire Faculty, ICGP (1993) How do your patients rate the service you provide? Forum (Irish Journal of General Practice) 5, 50-60.

11. Fitzpatrick R. \& Hopkins A. (1993) Measurement of patients' satisfaction with their care. In: Royal College of Physicians of London, pp. 4-7.

12. Holohan A.M., Newell D.J. \& Walker J.H. (1975) Practitioners, patients and the accident department. Hospital Health Service Review 71, 80-83.

13. Wood T.C.A. \& Cliff K.S. (1986) Accident and emergency departments - why people attend with minor injuries and complaints. Public Health 100, 15-29.

14. Reily P.M. (1981) Primary care and accident and emergency departments in an urban area. Journal of the Royal College of General Practitioners 31, 223-230.

15. Dale J. (1992) Primary care: the old bugbear of accident and emergency services [Editorial]. British Journal of General Practice 42, 90-91.

16. Blackwell B. (1962) Why patients come to a casualty department. Lancet i, 369-371. 